\title{
Complexity assessment and technical aspect of coronary angiogram and percutaneous coronary intervention following transcatheter aortic valve implantation
}

\author{
Nils Perrin, Amir Fassa, Antoine Baroz, Caroline Frangos, \\ Stephane Mock, Angela Frei, Murat Cimci, Sophie Degrauwe, \\ Marco Roffi, Juan Fernando Iglesias, Stephane Noble \\ Cardiology Division of the University Hospital of Geneva, Switzerland
}

\begin{abstract}
Background: Performing selective coronary angiogram (CA) and percutaneous coronary intervention (PCI) post transcatheter aortic valve implantation (TAVI) may be challenging with various success rates of coronary ostia engagement.

Methods: Among all patients who underwent CA and/or PCI after TAVI from our single center TAVI registry, ostia cannulation success was reported according to the quality of ostia engagement and artery opacification, and was classified as either selective, partially selective or non-selective but sufficient for diagnosis.

Results: Among the 424 consecutive TAVI procedures performed at the aforementioned institution, 20 (4.7\%) CA were performed in 19 (4.5\%) patients at a median time of 464 days post TAVI (25-75\% IQ: 213-634 days). CA were performed in 7 CoreValve, 9 Evolut $R, 1$ Evolut PRO and 2 Edwards Sapien 3 devices. Transradial vascular approach was attempted in 9 procedures $(45 \%$, right $n=6$ and left $n=3)$ and was successful in $8(40 \%)$ patients. A total of 20 left main artery ostium cannulation were attempted leading to a diagnostic CA in all of them with selective engagement in 65\%. Engagement of the right coronary artery in 2 out of 15 attempted cases failed due to a low ostium in conjunction with a high implantation of a CoreValve prosthesis. 11 PCI (55\% of CA) including 2 left main lesions were performed. In 4 patients (36.4\% of the PCI), an extension catheter was required to engage the left main. All planned PCI were successful.

Conclusions: Post TAVI CA and PCI are challenging but feasible even after supra-annular self-expandable valve implantation. (Cardiol J 2022; 29, 2: 197-204)
\end{abstract}

Key words: transcatheter aortic valve implantation, coronary angiogram, percutaneous coronary intervention, self-expandable transcatheter heart valve

\section{Introduction}

Aortic stenosis and coronary artery disease (CAD) share common risk factors and not surprisingly are often associated and the prevalence of both increases with an aging population $[1,2]$.
In the United Kingdom transcatheter aortic valve implantation (TAVI) registry, one, two and three vessel disease were found in $21.1 \%$, $11.5 \%$ and $13.2 \%$, respectively and thus almost half $(45.7 \%)$ of the patients had a concomitant CAD [3].

Address for correspondence: Stephane Noble, MD, Department of Medicine, Cardiology Division, Structural Heart Unit, University Hospitals of Geneva, 4, Rue Gabrielle-Perret-Gentil, 1211 Geneva 14, Switzerland, tel: 0041795533149 , fax: 00412237272 29, e-mail: stephane.noble@hcuge.ch

Received: 20.04.2020 Accepted: 11.05.2020 Early publication date: 20.05.2020

This article is available in open access under Creative Common Attribution-Non-Commercial-No Derivatives 4.0 International (CC BY-NC-ND 4.0) license, allowing to download articles and share them with others as long as they credit the authors and the publisher, but without permission to change them in any way or use them commercially. 


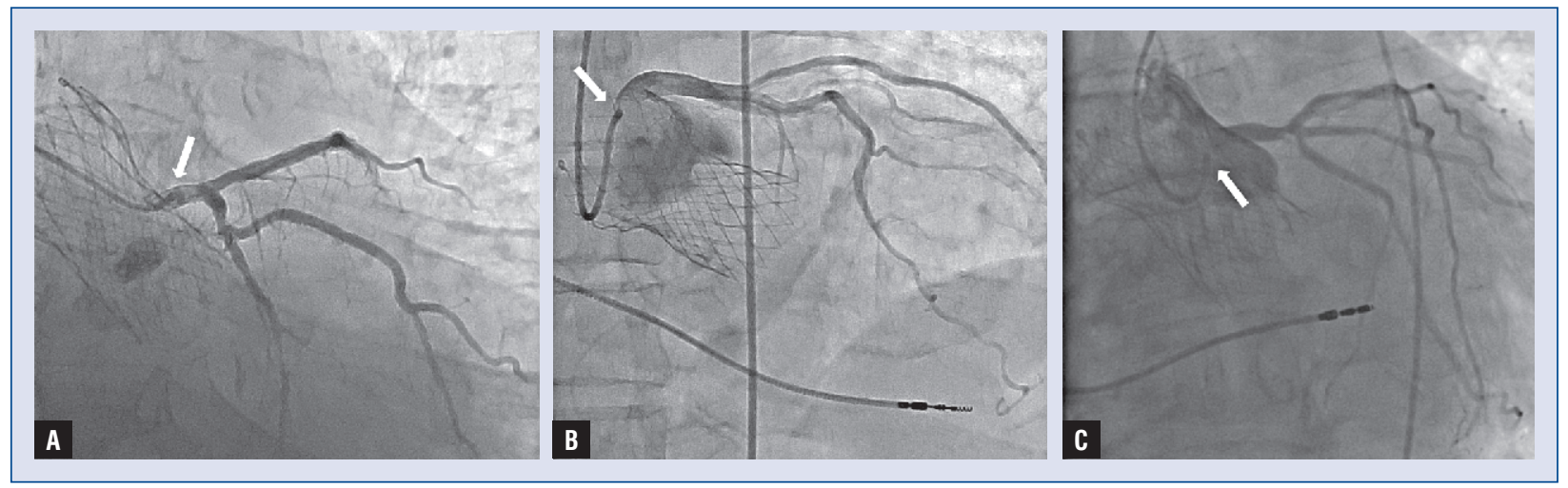

Figure 1. Selective (A), partially selective (B) or non-selective (C) coronary ostium cannulation. The white arrows show position of the catheter tip.

Management of stable CAD in patients with aortic stenosis planned for TAVI remains controversial. To date, there is no evidence showing the prognostic significance of performing coronary artery revascularization before, at the time or after the TAVI procedure $[4,5]$. Despite this controversial topic, the recent myocardial revascularization guidelines of the European Society of Cardiology suggest that patients undergoing TAVI with coronary artery stenosis $>70 \%$ in proximal segments should be considered for prior percutaneous coronary intervention (PCI) [6]. Similarly, the latest appropriate criteria for use of the American Society of Cardiology suggests coronary artery revascularization before TAVI [7]. More information will be obtained from the first randomized control trial ACTIVATION (Percutaneous Coronary Intervention Prior to Transcatheter Aortic Valve Implantation; ISRCTN75836930) currently recruiting patients and comparing PCI of significant coronary artery stenosis before TAVI versus medical management [8]. Nevertheless, the recent extension of TAVI to lower risk and younger patients will undoubtedly increase the need for future coronary angiogram (CA) and PCI post TAVI.

Performing selective $\mathrm{CA}$ and PCI post TAVI may represent a technical challenge with various success rates of coronary ostia engagement depending on the transcatheter heart valve type, supra-annular valves with long stent frames being potentially the most challenging. Additional factors such as the height of implantation and the orientation of the commissures may increase the challenge. Hereby reported are the technical characteristics and challenges faced when performing $\mathrm{CA}$ and $\mathrm{PCI}$ in patients post TAVI from this single center experience.

\section{Methods}

Data was extracted from all patients who underwent CA and/or PCI after TAVI from the present single center registry of transcatheter heart valves. Demographic data and TAVI procedure characteristics of the identified patients were taken from the local prospective TAVI registry. All patients gave written informed consent for the use of their anonymous related data for research.

All procedures studied were retrospectively reviewed by an interventional cardiologist (SN). For each CA, vascular access, contrast volume, fluoroscopy time and catheter type used were reported. Subjective complexity and the success of coronary artery cannulation were evaluated. Ostia cannulation success was reported according to the quality of ostia engagement and artery opacification, and classified as either selective, partially selective or non-selective but sufficient for diagnosis when the distal part of the arteries as well as all their branches were visualized (Fig. 1).

Before TAVI, all patients underwent multislice computed tomography to evaluate aortic annulus and root dimensions and calcifications. CA was routinely performed and patients with significant coronary artery lesions underwent PCI before or at the time of valve replacement at the operators' discretion. Significant lesions were defined according to the European guidelines on myocardial revascularization [6]. TAVI was performed mainly through the transfemoral approach as previously described [9]. Among patients analyzed in this report, implanted prosthesis were mainly Medtronic self-expandable devices (CoreValve $\mathrm{n}=7$, Evolut $\mathrm{R}$ $\mathrm{n}=9$ and Evolut PRO $\mathrm{n}=1$ ) with 2 Edwards Sapien 3 devices (Table 1). After TAVI, patients 
Table 1. Baseline characteristics.

\begin{tabular}{|c|c|}
\hline & Overall ( $n=19$ ) \\
\hline \multicolumn{2}{|l|}{ Sex } \\
\hline Female & $6(31.6 \%)$ \\
\hline Age, years (at the time of TAVI) & $77.7 \pm 7.2$ \\
\hline BMI $\left[\mathrm{kg} / \mathrm{m}^{2}\right]$ & $26.7 \pm 4.4$ \\
\hline STS score [\%] & $5.5 \pm 3.4$ \\
\hline \multicolumn{2}{|l|}{ Comorbidities: } \\
\hline Dyslipidemia & $15(78.9 \%)$ \\
\hline Diabetes mellitus & $8(42.1 \%)$ \\
\hline Hypertension & $15(78.9 \%)$ \\
\hline COPD & $6(31.6 \%)$ \\
\hline PVD & $4(21.1 \%)$ \\
\hline Previous MI & $4(21.1 \%)$ \\
\hline Previous CABG & $5(26.3 \%)$ \\
\hline Previous $\mathrm{PCl}$ & $10(52.6 \%)$ \\
\hline Previous cerebral stroke & $2(10.5 \%)$ \\
\hline Ejection fraction [\%] & $52.1 \pm 15.2$ \\
\hline \multicolumn{2}{|l|}{ Valve type: } \\
\hline CoreValve & $7(36.8 \%)$ \\
\hline Evolut R & $9(47.4 \%)$ \\
\hline Evolut PRO & $1(5.3 \%)$ \\
\hline Edwards Sapien & $2(10.5 \%)$ \\
\hline \multicolumn{2}{|l|}{ Valve size $[\mathrm{mm}]$ : } \\
\hline 23 & $5(26.3 \%)$ \\
\hline 26 & $4(21.1 \%)$ \\
\hline 29 & $6(31.6 \%)$ \\
\hline 31 & $3(15.8 \%)$ \\
\hline 34 & $1(5.3 \%)$ \\
\hline \multicolumn{2}{|l|}{ Valve position: } \\
\hline Low (> $8 \mathrm{~mm})$ & $2(10.5 \%)$ \\
\hline Optimal (2-8 mm) & $14(73.7 \%)$ \\
\hline High $(<2 \mathrm{~mm})$ & $3(15.8 \%)$ \\
\hline
\end{tabular}

Values are number (\%) or mean \pm standard deviation. BMI — body mass index; CABG - coronary artery bypass graft; COPD — chronic obstructive pulmonary disease; LVEF - left ventricular ejection fraction; $\mathrm{MI}$ - myocardial infarction; $\mathrm{PCl}$ - percutaneous coronary intervention; PVD - peripheral vascular disease; STS - Society of Thoracic Surgeons; TAVI — transcatheter aortic valve implantation

were prescribed a double antiplatelet therapy including clopidogrel for 3 months and acetylsalicylic acid (ASA) life-long. In patients with an indication for long-term oral anticoagulation, ASA was added for 1 month followed by anticoagulation alone unless they had undergone recent PCI ( $<6$ months).

Continuous variables are expressed as mean \pm standard deviation and categorical variables are shown as proportions (\%).

\section{Results}

Among 424 consecutive TAVI procedures (CoreValve 39.1\%, Evolut R and Pro 55.0\%, Edwards SAPIEN 5.4\%, Acurate neo 0.5\%) performed at the present institution between August 2008 and April 2019, respectively $32.0 \%$ and $7.8 \%$ had prior PCI or coronary artery bypass grafting (CABG). During the TAVI procedure concomitant PCI was performed in $9.0 \%$ of the cases. During follow-up, $20(4.7 \%)$ CA were performed in 19 (4.5\%) patients post TAVI. Mean age of the latter patients was $77.7 \pm 7.2$ years, with a mean Society of Thoracic Surgeons score of $5.5 \pm 3.4 \%$. Ten patients $(52.6 \%$ of CA) had prior PCI and 5 (26.3\%) patients had previously been treated by CABG prior to the TAVI procedure. Table 1 presents patient baseline demographic characteristics.

Coronary angiogram was performed at a median time of 464 days post TAVI (25-75\% IQ: 213-634 days) and at a mean time of $554 \pm 435$ days. Eight $(40.0 \%)$ CA were performed for acute coronary syndrome including two ST-segment elevation myocardial infarction (10.0\%), both involving the left circumflex artery.

Procedural characteristics of CA are detailed in Table 2. Transradial vascular approach was attempted in 9 procedures $(45.0 \%$, right $\mathrm{n}=6$ and left $\mathrm{n}=3$ ) with acceptable images in $8(40.0 \%)$ patients including 6 selective or partially selective ostia cannulation. One cross-over $(5.0 \%)$ from a right transradial to a transfemoral access was needed.

A total of 20 left main artery (LM) ostium cannulation were attempted leading to a diagnostic $\mathrm{CA}$ in all of them $(100 \%)$. Thirteen of these $(65.0 \%$, CoreValve $n=6 / 7$, Evolut R n $=6 / 9$, Edwards $n=1 / 2$ ) were selectively engaged (Table 2). In 12/20 CA $(60.0 \%)$, the use of one diagnostic catheter was sufficient to successfully cannulate the LM ostia using mostly 5 or 6 French Judkins Left (JL) 3.5 to 4.5 catheters. For the 8 remaining procedures, ostia engagement needed additional catheters including Multipurpose and/or Amplatz Left (AL) catheters. For the same patients, pre-TAVI CA were performed using standard catheters (JL or Judkins Right [JR]).

Right coronary artery (RCA) cannulation was attempted in only 15 cases ( $75.0 \%$ of $\mathrm{CA}$ ) because of known RCA total chronic occlusion, minor vessels with left dominance or low renal clearance in the absence of RCA territory ischemia based on electrocardiogram, echocardiogram or myocardial scintigraphy. It 
Table 2. Procedural characteristics.

\begin{tabular}{|c|c|}
\hline & $\begin{array}{c}\text { Overall } \\
(C A, n=20)\end{array}$ \\
\hline \multicolumn{2}{|l|}{ Indication of CA: } \\
\hline STEMI & $2(10.0 \%)$ \\
\hline NSTEMI & $6(30.0 \%)$ \\
\hline Stable angina & $9(45.0 \%)$ \\
\hline Other & $3(15.0 \%)$ \\
\hline Days post-TAVI & $554 \pm 435$ \\
\hline \multicolumn{2}{|l|}{ Vascular access: } \\
\hline Radial right & $5(25.0 \%)$ \\
\hline Radial left & $3(15.0 \%)$ \\
\hline Femoral & $12(60.0 \%)$ \\
\hline \multicolumn{2}{|c|}{ Difficulty of coronary artery cannulation: } \\
\hline Easy & $7(35.0 \%)$ \\
\hline Intermediate & $7(35.0 \%)$ \\
\hline Difficult & $6(30.0 \%)$ \\
\hline \multicolumn{2}{|l|}{$\begin{array}{l}\text { Success of coronary artery } \\
\text { selective injection: }\end{array}$} \\
\hline $\operatorname{LM}(n=20):$ & $9(45.0 \%)$ \\
\hline Selective & $4(20.0 \%)$ \\
\hline Partially-selective & $7(35.0 \%)$ \\
\hline Non-selective & $0(0 \%)$ \\
\hline \multicolumn{2}{|l|}{ Failure } \\
\hline $\operatorname{RCA}(n=15):$ & $7(35.0 \%)$ \\
\hline Selective & $3(15.0 \%)$ \\
\hline Incomplete selective & $3(15.0 \%)$ \\
\hline Non-selective & $2(10.0 \%)$ \\
\hline \multicolumn{2}{|l|}{ Failure } \\
\hline \multicolumn{2}{|c|}{ Number of catheters used for cannulation: } \\
\hline LM & $\begin{array}{c}2.0 \pm 1.4 \\
(\min .1, \max .5)\end{array}$ \\
\hline RCA & $1.2 \pm 0.8$ \\
\hline Number of $\mathrm{PCl}$ performed: & $11(55.0 \%)$ \\
\hline LM & $3(15.0 \%)$ \\
\hline LAD & $3(15.0 \%)$ \\
\hline LCx & $3(15.0 \%)$ \\
\hline $\mathrm{RCA}$ & $2(10.0 \%)$ \\
\hline Mean procedural time [min]: & $47.0 \pm 31.1$ \\
\hline CA alone & $24.2 \pm 18.7$ \\
\hline $\mathrm{CA}+\mathrm{PCl}$ & $77.0 \pm 21.6$ \\
\hline $\begin{array}{l}\text { Mean fluoroscopy time [min], } \\
\text { overall: }\end{array}$ & $25.2 \pm 14.7$ \\
\hline CA alone & $13.6 \pm 7.9$ \\
\hline $\mathrm{CA}+\mathrm{PCl}$ & $35.5 \pm 11.1$ \\
\hline $\begin{array}{l}\text { Amount of contrast used }[\mathrm{mL}] \text {, } \\
\text { overall: }\end{array}$ & $125.0 \pm 55.8$ \\
\hline CA alone & $78.8 \pm 29.1$ \\
\hline $\mathrm{CA}+\mathrm{PCl}$ & $166.1 \pm 38.1$ \\
\hline
\end{tabular}

Values are number (\%) or mean \pm standard deviation. CA - coronary angiography; LAD — left anterior descending coronary artery; LCx - left circumflex coronary artery; LM - left main coronary artery; NSTEMI - non-ST segment elevation myocardial infarction; $\mathrm{PCl}$ - percutaneous coronary intervention; RCA — right coronary artery; STEMI — ST segment elevation myocardial infarction; $\mathrm{TAVI}$ - transcatheter aortic valve implantation was possible to engage selectively and non-selectively respectively in $10(66.7 \%)$ and $3(20.0 \%)$ RCA using the JR catheter in 8/15 RCA CA and an additional catheter (including AL, Tiger, Multipurpose, 3DRC and right coronary bypass catheter) in the remaining patients. Failure to engage the RCA in 2 cases occurred due to a low ostium in conjunction with a high implantation of a CoreValve prosthesis (implantation depth at $0 \mathrm{~mm}$ in both cases).

Eleven coronary artery lesions (55.0\% of CA) were treated including $2 \mathrm{LM}$ lesions (Table 2). One of the LM PCI (Edwards case) was performed with extracorporeal membrane oxygenation (ECMO) support due to a very calcified distal LM subocclusion requiring rotablation, a significant proximal left anterior descending and circumflex artery stenosis and 2 occluded saphenous vein grafts. Withdrawing the ECMO was accomplished at the end of the procedure without any complications. In 4 patients (36.4\% of the PCI), an extension catheter (GuideLiner, Vascular Solutions Inc.) was needed to help the appropriate guiding catheter engagement in the LM. The exchange from the diagnostic catheter to the guiding catheter was performed over an extended 0.014 wire (extension wire Asahi, Tokyo, Japan) and a second guidewire, either a 0.35 or 0.18 wire. All planned PCI were successful. No case of hemodynamically significant acute prosthesis dysfunction was reported after CA or PCI.

\section{Discussion}

This descriptive study aimed to look at the technical characteristics and challenges of performing CA and PCI post TAVI from a single center experience. The main findings and learning points derived from this study are as follows:

- The need for CA and PCI after TAVI is low (4.7\% and $2.6 \%$, respectively);

- Post TAVI CA and PCI remain challenging, but are feasible even after supra-annular selfexpandable valve prosthesis implantation;

- With self-expanding devices with a long stent frame and reduced possibilities of standard catheter manipulation, favoring the left radial or transfemoral approaches over the right radial approach is herein suggested;

- Catheter extension facilitates appropriate guiding catheter engagement in the coronary ostia and were used in $36.4 \%$ of the cases.

At our institution, all patients underwent pre-TAVI coronary artery assessment with revascularization of clinically indicated lesions at the operators' discretion. This led to a low incidence 
of CA following TAVI (4.7\%) but similar to a rate published the series [10-12]. CA was performed at a median time of 464 days post TAVI (25-75\% IQ: 213-634 days).

When considering coronary access, post TAVI, different challenges have been reported, particularly with self-expandable prostheses [13]. Indeed, among the largest observational studies published by Zivelonghi et al. [11], only standard catheters were used to cannulate coronary ostia of 41 patients after Sapien 3 (Edwards Lifesciences, Irvine, California) prosthesis implantation. Challenges may be encountered in the case of large Sapien prostheses, highly implanted with borderline coronary ostium height. In this setting, the stent frame of the Edwards valve will most commonly cover the coronary ostia. Therefore, in order to cannulate the ostia, the catheter will have to cross the stent frame, similarly as with a supra-annular prosthesis with a long stent frame. This raises several technical challenges due to anatomical, device-related and procedural considerations.

The space to manipulate the catheter is reduced in the presence of a long stent frame, even more so with a waisted frame such as the CoreValve. Of note, the stent frame shape of the Evolut $R$ and Pro have had some iteration with respect to the waist shape and cell size. Since with right radial access, shorter catheters are commonly used than with left radial or transfemoral approaches, in the context of a CoreValve frame which reduces the width of the aortic root, it is highly challenging to manipulate the classical catheters. Therefore, we believe that the left radial or transfemoral approaches should be favored. In a different series reported (Table 3) [10, 11, 14-19], most operators also preferred alternative access to the right radial access. In a series from an expert radial center, transradial rate (without data for left or right) was only $70 \%$ compared to more than $90 \%$ in their global activity [20]. In agreement with Yudi et al. [13], who recommends the use of $5 \mathrm{~F}$ or $6 \mathrm{~F}$ guiding catheters and avoiding $7 \mathrm{~F}$ or $8 \mathrm{~F}$ guiding catheters since they are too bulky within the limited space offered by the stent frame.

Valve implantation depth also plays a major role in supra-annular or long stent frame prostheses. High valve implantation (particularly with low coronary ostium position) might place the sealing skirt at the level of the coronary ostium and prevent coaxial cannulation [20]. In this situation, the catheter has to pass through the stent struts above the coronary ostia. From previous experience, among 3 highly implanted prosthesis, borderline-selective and non-selective left side CA, with standard JL catheters among 2 of them were performed. In a third patient the use of additional catheters was needed, finally succeeding with an EBU catheter. On the other hand, right $\mathrm{CA}$ with highly implanted prosthesis was unsuccessful in 2 of these patients and was not performed in the remaining patient due to known chronic total occlusion.

Importantly, coronary ostia should be engaged through a diamond at the level of the ostium as much as possible, since catheter kinking and entrapment has been described when engaging from a diamond below the ostium with catastrophic outcomes [21].

Overall, diagnostic left and right CA were performed in $100 \%$ and $90 \%$ respectively of patients at the expense of additional manipulations using up to 5 different catheters and prolonged fluoroscopic time (13.6 $\pm 7.9 \mathrm{~min}$ for diagnostic CA alone).

About half of patients of the cohort (48\%) underwent PCI. Whereas unselective coronary injection might be sufficient for diagnostic purposes, coaxial catheter engagement is important to increase support and perform a safe PCI. In case of ostium cannulation difficulties, a coronary wire can be placed in the LM or RCA with or without inflating a balloon (anchoring balloon technique) and be used as a rail guiding the catheter. If unsuccessful, an extension catheter can afford selective coronary ostium cannulation. With these techniques, the present study was able to successfully perform all planned PCI using an extension catheter in $36 \%$ of patients. Of note, in 3 cases where it was difficult to engage the ostium with the diagnostic catheter, an 0.014 extra-support blue Sion wire with an extension wire (Asahi) was introduced into the coronary artery and in parallel, an additional $260 \mathrm{~cm} 0.18$ " or 0.35 " stiff wire in the aortic root in order to exchange the diagnostic catheter for the guiding catheter. To overcome the technical difficulty to cannulate the coronary ostia, designing dedicated coronary guiding catheters (i.e. orientable, different shapes) might be of interest for post TAVI PCI.

Finally, transcatheter heart valves are deployed in the aortic root without consistent prosthetic and native leaflet superposition. The resultant commissural mis-alignment could lead to coronary ostium overlap compromising future coronary access $[22,23]$. In a pilot study, Tang et al. [24] evaluated commissural orientation and coronary overlap according to their initial deployment orientation, by computed tomography imaging. After the implantation of a Medtronic Evolut valve, 


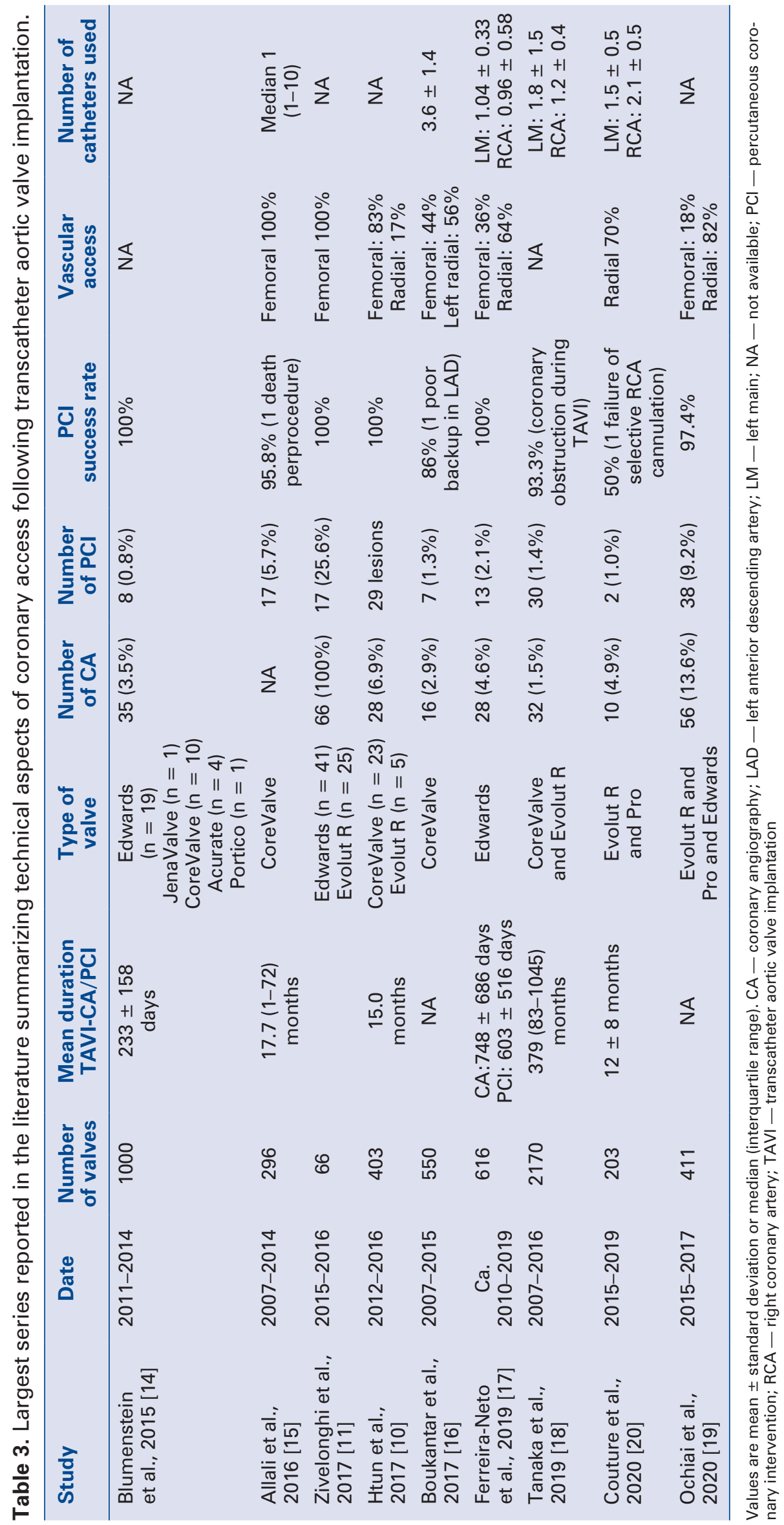


ostium overlap occurred more frequently when the capsule hat orientation faced the inner curve of the aorta or was in the center but posteriorly located in a standard left oblique view.

Durability of transcatheter aortic heart valves have recently shown favorable results at 5 years, but limited data above 7 years [25] remains. However, when treating younger patients with longer life expectancy, valve degeneration might occur and can be managed in selected patients by implanting a second transcatheter heart valve in the degenerated prosthesis (TAV-in-TAV) [26]. The degenerated prosthetic leaflets will thus be pushed against the stent frame at the expense of increased difficulty to pass through the struts. Here again, a short stent frame prosthesis implanted in a previous intra-annular or supra-annular prosthesis will only rarely compromise coronary access contrary to supra-annular prosthesis implanted in a degenerated long or short stent frame prosthesis. In the worst case of TAV-in-TAV using 2 long stent frame prosthesis, overlap of the 2 misaligned commissures can lead to a hermetic tissue obstruction up to the sinotubular junction and definitively prevent coronary access [27].

\section{Limitations of the study}

The main limitation of this study is its retrospective design and the inclusion of a small number of patients due to the low incidence of CA post TAVI. Procedural or technical predictors of CA success were thus not calculated because of the small statistical power precluding any relevant results. CA were performed by experienced operators in coronary interventions but vary in experience in the TAVI field. Even though this might cause an overestimation in subjective difficulty in coronary ostia engagement, it reflects real life in the catheterization laboratory.

\section{Conclusions}

Post TAVI CA and PCI are challenging but feasible even after supra-annular self-expandable valve implantation. High implantation of TAVI reduces the need for new pacemaker implantation, but may increase the challenge of coronary artery cannulation especially if coronary ostia are low. Use of a catheter extension is often needed to perform PCI, post TAVI. Valve design according to patient anatomical characteristics should be part of the prosthesis selection process at the time of TAVI procedure as it could affect future coronary access. In addition, orientation of the commissure during deployment seems to be an important feature to develop for new devices in order to facilitate recannulation of coronary arteries.

Conflict of interest: Dr. Stephane Noble reports to be a consultant for Medtronic CoreValve and Evolut R (trainer for new centers performing TAVI). Dr. Marco Roffi received institutional research grants from Abbott Vascular, Boston Scientific, Biotronik, Biosensor and Medtronic. The other authors declare no disclosure. Medtronic had no role in the design, subject recruitment or preparation of this report.

\section{References}

1. Nkomo V, Gardin J, Skelton T, et al. Burden of valvular heart diseases: a population-based study. Lancet. 2006; 368(9540): 1005-1011, doi: 10.1016/s0140-6736(06)69208-8.

2. Odden MC, Coxson PG, Moran A, et al. The impact of the aging population on coronary heart disease in the United States. Am J Med. 2011; 124(9): 827-33.e5, doi: 10.1016/j.amjmed.2011.04.010, indexed in Pubmed: 21722862.

3. Snow TM, Ludman P, Banya W, et al. Management of concomitant coronary artery disease in patients undergoing transcatheter aortic valve implantation: the United Kingdom TAVI Registry. Int J Cardiol. 2015; 199: 253-260, doi: 10.1016/j.ijcard.2015.06.166, indexed in Pubmed: 26209948.

4. Ramee S, Anwaruddin S, Kumar G, et al. The rationale for performance of coronary angiography and stenting before transcatheter aortic valve replacement: from the interventional section leadership council of the american college of cardiology. JACC Cardiovasc Interv. 2016; 9(23): 2371-2375, doi: 10.1016/j. jcin.2016.09.024, indexed in Pubmed: 27931592.

5. Kotronias RA, Teitelbaum M, Webb JG, et al. Transcatheter aortic valve implantation with or without percutaneous coronary artery revascularization strategy: a systematic review and metaanalysis. J Am Heart Assoc. 2017; 6(6): 1759-1771, doi: 10.1161/ JAHA.117.005960, indexed in Pubmed: 28655733.

6. Neumann FJ, Sousa-Uva M, Ahlsson A, et al. 2018 ESC/EACTS Guidelines on myocardial revascularization. Eur Heart J. 2019; 40(2): 87-165, doi: 10.1093/eurheartj/ehy394, indexed in Pubmed: 30165437.

7. Patel MR, Calhoon JH, Dehmer GJ, et al. ACC/AATS/AHA/ /ASE/ASNC/SCAI/SCCT/STS 2017 Appropriate Use Criteria for Coronary Revascularization in Patients With Stable Ischemic Heart Disease : A Report of the American College of Cardiology Appropriate Use Criteria Task Force, American Association for Thoracic Surgery, American Heart Association, American Society of Echocardiography, American Society of Nuclear Cardiology, Society for Cardiovascular Angiography and Interventions, Society of Cardiovascular Computed Tomography, and Society of Thoracic Surgeons. J Nucl Cardiol. 2017; 24(5): 1759-1792, doi: 10.1007/s12350-017-0917-9, indexed in Pubmed: 28608183.

8. Khawaja MZ, Wang D, Pocock S, et al. The percutaneous coronary intervention prior to transcatheter aortic valve implantation (ACTIVATION) trial: study protocol for a randomized controlled trial. Trials. 2014; 15: 300, doi: 10.1186/1745-6215-15-300, indexed in Pubmed: 25059340. 
9. Perrin N, Roffi M, Frei A, et al. Thirty-day outcome following corevalve evolut $r$ transcatheter aortic valve implantation: an all-comers prospective study. Rev Esp Cardiol (Engl Ed). 2017; 70(9): 713-719, doi: 10.1016/j.rec.2016.11.024, indexed in Pubmed: 28034684.

10. Htun WW, Grines C, Schreiber T. Feasibility of coronary angiography and percutaneous coronary intervention after transcatheter aortic valve replacement using a Medtronic ${ }^{\mathrm{TM}}$ self-ex- $^{-}$ pandable bioprosthetic valve. Catheter Cardiovasc Interv. 2018; 91(7): 1339-1344, doi: 10.1002/ccd.27346, indexed in Pubmed: 28988450.

11. Zivelonghi C, Pesarini G, Scarsini R, et al. Coronary catheterization and percutaneous interventions after transcatheter aortic valve implantation. Am J Cardiol. 2017; 120(4): 625-631, doi: 10.1016/j.amjcard.2016.10.046, indexed in Pubmed: 27964903.

12. Chakravarty T, Sharma R, Abramowitz Y, et al. Outcomes in patients with transcatheter aortic valve replacement and left main stenting: the TAVR-LM registry. J Am Coll Cardiol. 2016; 67(8): 951-960, doi: 10.1016/j.jacc.2015.10.103, indexed in Pubmed: 26916485.

13. Yudi MB, Sharma SK, Tang GHL, et al. Coronary angiography and percutaneous coronary intervention after transcatheter aortic valve replacement. J Am Coll Cardiol. 2018; 71(12): 1360-1378, doi: 10.1016/j.jacc.2018.01.057, indexed in Pubmed: 29566822.

14. Blumenstein J, Kim WK, Liebetrau C, et al. Challenges of coronary angiography and intervention in patients previously treated by TAVI. Clin Res Cardiol. 2015; 104(8): 632-639, doi: 10.1007/ s00392-015-0824-5, indexed in Pubmed: 25720330.

15. Allali A, El-Mawardy M, Schwarz B, et al. Incidence, feasibility and outcome of percutaneous coronary intervention after transcatheter aortic valve implantation with a self-expanding prosthesis. Results from a single center experience. Cardiovasc Revasc Med. 2016; 17(6): 391-398, doi: 10.1016/j.carrev.2016.05.010, indexed in Pubmed: 27396607.

16. Boukantar M, Gallet R, Mouillet G, et al. Coronary procedures after TAVI with the self-expanding aortic bioprosthesis medtronic corevalve ${ }^{\mathrm{TM}}$, not an easy matter. J Interv Cardiol. 2017; 30(1): 56-62, doi: 10.1111/joic.12363, indexed in Pubmed: 28078734.

17. Ferreira-Neto AN, Puri R, Asmarats L, et al. Clinical and technical characteristics of coronary angiography and percutaneous coronary interventions performed before and after transcatheter aortic valve replacement with a balloon-expandable valve. J Interv Cardiol. 2019; 2019: 3579671, doi: 10.1155/2019/3579671, indexed in Pubmed: 31772527.

18. Tanaka A, Jabbour RJ, Testa L, et al. Incidence, technical safety, and feasibility of coronary angiography and intervention fol- lowing self-expanding transcatheter aortic valve replacement. Cardiovasc Revasc Med. 2019; 20(5): 371-375, doi: 10.1016/j. carrev.2019.01.026, indexed in Pubmed: 30857975.

19. Ochiai T, Chakravarty T, Yoon SH, et al. Coronary access after TAVR. JACC Cardiovasc Interv. 2020; 13(6): 693-705, doi: 10.1016/j.jcin.2020.01.216, indexed in Pubmed: 32192689.

20. Couture T, Faroux L, Junquera L, et al. Interaction between selfexpanding transcatheter heart valves and coronary ostia: an angiographically based analysis of the evolut $\mathrm{r} / \mathrm{pro}$ valve system. J Invasive Cardiol. 2020; 32(4): 123-128, indexed in Pubmed: 32160151.

21. Harhash A, Ansari J, Mandel L, et al. STEMI After TAVR: Procedural Challenge and Catastrophic Outcome. JACC Cardiovasc Interv. 2016; 9(13): 1412-1413, doi: 10.1016/j.jcin.2016.04.043, indexed in Pubmed: 27388832.

22. Tang GHL, Zaid S, Ahmad H, et al. Transcatheter valve neocommissural overlap with coronary orifices after transcatheter aortic valve replacement. Circ Cardiovasc Interv. 2018; 11(10): e007263, doi: 10.1161/CIRCINTERVENTIONS.118.007263, indexed in Pubmed: 30354640.

23. Fuchs A, Kofoed KF, Yoon SH, et al. Commissural alignment of bioprosthetic aortic valve and native aortic valve following surgical and transcatheter aortic valve replacement and its impact on valvular function and coronary filling. JACC Cardiovasc Interv. 2018; 11(17): 1733-1743, doi: 10.1016/j.jcin.2018.05.043, indexed in Pubmed: 30121280.

24. Tang GHL, Zaid S, Gupta E, et al. Impact of initial evolut transcatheter aortic valve replacement deployment orientation on final valve orientation and coronary reaccess. Circ Cardiovasc Interv. 2019; 12(7): e008044, doi: 10.1161/CIRCINTERVENTIONS.119.008044, indexed in Pubmed: 31272225.

25. Mack M, Leon M, Smith C, et al. 5-year outcomes of transcatheter aortic valve replacement or surgical aortic valve replacement for high surgical risk patients with aortic stenosis (PARTNER 1): a randomised controlled trial. The Lancet. 2015; 385(9986): 2477-2484, doi: 10.1016/s0140-6736(15)60308-7.

26. Barbanti M, Webb JG, Tamburino C, et al. Outcomes of redo transcatheter aortic valve replacement for the treatment of postprocedural and late occurrence of paravalvular regurgitation and transcatheter valve failure. Circ Cardiovasc Interv. 2016; 9(9): e003930, doi: 10.1161/CIRCINTERVENTIONS.116.003930, indexed in Pubmed: 27578840.

27. Søndergaard L. Transcatheter aortic valve implantation: don't forget the coronary arteries! EuroIntervention. 2018; 14(2): 147 -149, doi: 10.4244/eijv14i2a24, indexed in Pubmed: 29937429. 